\title{
Vasorelaxant and antihypertensive effects of formononetin through endothelium-dependent and -independent mechanisms
}

\author{
Tao SUN, Rui LIU, Yong-xiao CAO* \\ Department of Pharmacolgy, Xi-an Jiaotong University College of Medicine, Xi-an 710061, China
}

\begin{abstract}
Aim: To investigate the mechanisms underlying the vasorelaxant effect of formononetin, an 0-methylated isoflavone, in isolated arteries, and its antihypertensive activity in vivo.

Methods: Arterial rings of superior mesenteric arteries, renal arteries, cerebral basilar arteries, coronary arteries and abdominal aortas were prepared from SD rats. Isometric tension of the arterial rings was recorded using a myograph system. Arterial pressure was measured using tail-cuff method in spontaneously hypertensive rats.

Results: Formononetin $(1-300 \mu \mathrm{mol} / \mathrm{L})$ elicited relaxation in arteries of the five regions that were pre-contracted by $\mathrm{KCl}(60 \mathrm{mmol} / \mathrm{L})$, U46619 (1 $\mu \mathrm{mol} / \mathrm{L})$ or phenylephrine $(10 \mu \mathrm{mol} / \mathrm{L})$. The formononetin-induced relaxation was reduced by removal of endothelium or by pretreatment with L-NAME $(100 \mu \mathrm{mol} / \mathrm{L})$. Under conditions of endothelium denudation, formononetin (10, 30, and 100 $\mu \mathrm{mol} / \mathrm{L})$ inhibited the contraction induced by $\mathrm{KCl}$ and that induced by $\mathrm{CaCl}_{2}$ in $\mathrm{Ca}^{2+}$-free depolarized medium. In the absence of extracellular $\mathrm{Ca}^{2+}$, formononetin $(10,30$, and $100 \mu \mathrm{mol} / \mathrm{L})$ depressed the constriction caused by phenylephrine (10 $\left.\mu \mathrm{mol} / \mathrm{L}\right)$, but did not inhibit the tonic contraction in response to the addition of $\mathrm{CaCl}_{2}(2 \mathrm{mmol} / \mathrm{L})$. The contraction caused by caffeine $(30 \mathrm{mmol} / \mathrm{L})$ was not inhibited by formononetin $(100 \mu \mathrm{mol} / \mathrm{L})$. Formononetin $(10$ and $100 \mu \mathrm{mol} / \mathrm{L})$ reduced the change rate of $\mathrm{Ca}^{2+}$-fluorescence intensity in response to $\mathrm{KCl}(50 \mathrm{mmol} / \mathrm{L})$. In spontaneously hypertensive rats, formononetin (5, 10, and $20 \mathrm{mg} / \mathrm{kg})$ slowly lowered the systolic, diastolic and mean arterial pressure.

Conclusion: Formononetin causes vasodilatation via two pathways: (1) endothelium-independent pathway, probably due to inhibition of voltage-dependent $\mathrm{Ca}^{2+}$ channels and intracellular $\mathrm{Ca}^{2+}$ release; and (2) endothelium-dependent pathway by releasing NO. Both the pathways may contribute to its antihypertensive effect.
\end{abstract}

Keywords: formononetin; arterial rings; vasodilatation; voltage-dependent $\mathrm{Ca}^{2+}$ channel; intracellular $\mathrm{Ca}^{2+}$ release; nitric oxide; spontaneously hypertensive rats; blood pressure

Acta Pharmacologica Sinica (2011) 32: 1009-1018; doi: 10.1038/aps.2011.51

\section{Introduction}

Hypertension is one of the most common cardiovascular diseases, which is a major risk factor for endothelial dysfunction, metabolic syndrome, diabetes, renal dysfunction, congestive heart failure, coronary artery diseases and stroke ${ }^{[1]}$. Clinically, various antihypertensive drugs such as diuretics, centrally acting adrenergic drugs, vasodilators, calcium channel blockers and angiotensin converting enzyme/receptor blockers have been used to treat hypertension. However, the efficacy of these drugs is only $40 \%-60 \%$, and usually two or more antihypertensive drugs from different categories need to be combined to achieve optimal results. In addition, the side effects

\footnotetext{
* To whom correspondence should be addressed.

E-mail yxy@xjtu.edu.cn

Received 2010-11-30 Accepted 2011-03-29
}

from these medications are an important concern ${ }^{[2]}$.

To develop a safe and effective way for managing hypertension has long been a challenge for medical researchers and doctors. Many traditional Chinese medicinal herbs with vasorelaxant properties are conventionally used to treat hypertension ${ }^{[3]}$. Recently, interest in the use of medicinal herbs has risen exponentially, due to their low toxicity and wonderful therapeutical performance ${ }^{[4]}$. Therefore, we started a project to find a novel antihypertensive compound with vasorelaxant activity from traditional Chinese medicinal plants that are used as antihypertensive agents.

Phytoestrogens are plant substances found in many foods, which are structurally or functionally similar to estradiol. They have attracted much attention because of their potential beneficial role in prevention and treatment of cardiovascular diseases, bone metabolism disorders, breast cancers, 
and menopausal symptoms ${ }^{[5-9]}$. Isoflavones are a class of phytoestrogens naturally sourced from legumes such as soy beans and red clover ${ }^{[10]}$. Some isoflavones have been reported for treatment of hypertension, coronary heart diseases and cardiac infarct ${ }^{[11-14]}$ through dilating arteries and increasing blood flow $^{[15,16]}$. Formononetin, an $O$-methylated isoflavone, is contained in the roots of Astragalus membranaceus ${ }^{[17,18]}$, liquorice ${ }^{[19]}$, black cohosh ${ }^{[20,21]}$ and Trifolium pratense $\mathrm{L}^{[22]}$. Medicinal herbs containing formononetin have been used to treat cardiovascular diseases including hypertension in Asia for centuries ${ }^{[23]}$. Recently, Wu et al reported that formononetin has a vasorelaxant activity in isolated rat aorta rings ${ }^{[9]}$. However, the antihypertensive activity of formononetin and its vasorelaxant effect on arteries in different regions have not yet been studied. The aim of the present study was to determine whether formononetin is contributory to treating hypertension, and further to explore the potential mechanisms of its antihypertensive activity.

\section{Materials and methods} Drugs and reagents

Formononetin was supplied by Department of Chemistry, Shaanxi Normal University, China. Phenylephrine, 9,11-dideoxy-11 alpha, 9 alpha-epoxymethano-prostaglandin $\mathrm{F}_{2}$ alpha (U46619), 5-hydroxytryptamine (5-HT), noradrenaline, Triton X-100, propranolol, glibenclamide, tetraethylammonium, acetylcholine chloride $(\mathrm{ACh})$, indomethacin, $N^{\omega}$-nitro-L-arginine methyl ester (L-NAME), verapamil, lacidipine, sodium nitroprusside (SNP), caffeine, and dimethyl sulphoxide (DMSO) were purchased from Sigma Aldrich (St Louis, MO, USA). Fluo-3/AM was obtained from Biotium (Hayward, CA, USA). All other reagents were of analytical grade. Formononetin was dissolved in DMSO for in vitro use and dissolved in $10 \%$ Tween 80 solution for in vivo use. Fluo-3/AM and glibenclamide were dissolved in DMSO. Indomethacin was dissolved in ethanol. Other substances were dissolved in double distilled water. The concentrations are expressed as the final molar concentrations in the tissue baths.

\section{Animals}

Sprague-Dawley (SD) rats were obtained from Experimental Animal Center of $\mathrm{Xi}$-an Jiaotong University College of Medicine, China. Male spontaneously hypertensive rats (SHRs) aged 20 weeks were obtained from Shanghai Slack Laboratory Animal Co Ltd, China. The study was approved by Ethics Committee of $\mathrm{Xi}$-an Jiaotong University College of Medicine according to the principles outlined in the Declaration of Helsinki.

\section{Arterial rings preparation}

SD rats weighing 250-300 $\mathrm{g}$ were sacrificed by $\mathrm{CO}_{2}$. The rat superior mesenteric arteries, renal arteries, cerebral basilar arteries, coronary arteries, and abdominal aortas were gently removed. The arteries were immersed in cold oxygenated Krebs solution containing the following composition (mmol/L): $\mathrm{NaCl} 119, \mathrm{NaHCO}_{3} 15, \mathrm{KCl} 4.6, \mathrm{MgCl}_{2}$ 1.2,
$\mathrm{NaH}_{2} \mathrm{PO}_{4} 1.2, \mathrm{CaCl}_{2} 1.5$ and glucose 5.5. The arteries were dissected free of adhering tissue under a microscope. In the endothelium-denuded experiments, the endothelium was denuded by perfusion of the vessels for $10 \mathrm{~s}$ with $0.1 \%$ Triton X-100 followed by another $10 \mathrm{~s}$ with Krebs solution ${ }^{[24]}$. The vessels were then cut into $1 \mathrm{~mm}$ cylindrical segments.

\section{Myograph experiments}

The artery segments were threaded on two $40-\mu \mathrm{m}$-diameter stainless steel wires and mounted in Mulvany-Halpern myographs (Danish Myo Technology A/S, Aarhus, Denmark). One wire was connected to a force displacement transducer and attached to an analog-to-digital converter unit (AD Instruments, Hastings, UK). The other wire was attached to a movable displacement device, allowing fine adjustments of vascular tension by varying the distance between the wires. The data were recorded using Chart ${ }^{\mathrm{TM}}$ (AD Instruments, Hastings, UK). The mounted artery segments were immersed in temperature-controlled $\left(37^{\circ} \mathrm{C}\right)$ tissue baths containing $5 \mathrm{~mL}$ Krebs solution. The solution was continuously gassed with $5 \% \mathrm{CO}_{2}$ in $\mathrm{O}_{2}$ resulting in a physiological $\mathrm{pH}$ at 7.4. The artery segments were equilibrated for $1.5 \mathrm{~h}$ before the experiments, and the cerebral artery and coronary artery segments were given a resting tension of $1.5 \mathrm{mN}$, while other segments a $3-\mathrm{mN}$ tension. The contractile capacity of each vessel segment was tested by exposing the segment to a $\mathrm{K}^{+}$-rich Krebs solution (with $60 \mathrm{mmol} / \mathrm{L} \mathrm{KCl}$ ) in which $\mathrm{NaCl}$ was exchanged for an equimolar concentration of $\mathrm{KCl}$. Two reproducible high- $\mathrm{K}^{+}$ contractions were obtained for standardization of the preparations.

The completeness of endothelium denudation was tested with ACh $(10 \mu \mathrm{mol} / \mathrm{L})$ after cerebral basilar arteries and coronary arteries were pre-contracted with $0.3 \mu \mathrm{mol} / \mathrm{L} 5-\mathrm{HT}$, and mesenteric arteries, renal arteries and abdominal aortas were pre-contracted with $10 \mu \mathrm{mol} / \mathrm{L}$ noradrenaline. No relaxation in response to $\mathrm{ACh}$ in the denuded preparation was regarded as functional removal of the endothelium. The endothelium was considered intact when such an ACh response caused more than $30 \%$ relaxation ${ }^{[25]}$.

To determine the relaxant effect, the segments were precontracted, and once the sustained tension was obtained, formononetin (1-300 $\mu \mathrm{mol} / \mathrm{L})$ was added cumulatively to induce a concentration-dependent response. Some experiments were performed in both endothelium-intact and endothelium-free mesenteric arteries to determine whether the relaxant effect of formononetin was endothelium-dependent. Phenylephrine and formononetin were added after some mesenteric artery rings were pre-treated with L-NAME and/or indomethacin for $20 \mathrm{~min}$ so as to determine the involvement of nitric oxide (NO), prostaglandins (PGs) and endothelium-derived hyperpolarizing factor (EDHR) in the relaxant effect of formononetin. In order to evaluate the role of potassium $\left(\mathrm{K}^{+}\right)$channels and $\beta$-adrenoceptors in the vasorelaxant effect of formononetin, some mesenteric artery rings were pre-treated with tetraethylammonium, $\mathrm{BaCl}_{2}$, glibenclamide, or propranolol for 20 min before the addition of vasoconstrictor and formononetin. 
To determine the involvement of voltage-dependent $\mathrm{Ca}^{2+}$ channels (VDCC), $\mathrm{a}_{1}$-adrenoceptors and 5-HT receptors in the relaxant effect of formononetin, concentration-response curves of $\mathrm{KCl}, \mathrm{CaCl}_{2}$ in $\mathrm{Ca}^{2+}$-free depolarized medium, phenylephrine and 5-HT in the presence of formononetin were constructed. Some mesenteric artery rings were incubated in a $\mathrm{Ca}^{2+}$-free Krebs solution to determine whether the relaxant effect of formononetin was due to its inhibition of intracellular $\mathrm{Ca}^{2+}$ release or extracellular $\mathrm{Ca}^{2+}$ influx ${ }^{[26,27]}$.

The smooth muscle function was assessed at the end of each experiment. The mesenteric arteries, renal arteries and abdominal aortas were pre-constricted with phenylephrine (10 $\mu \mathrm{mol} / \mathrm{L})$, while the cerebral basilar arteries and coronary arteries were pre-contracted with $0.3 \mu \mathrm{mol} / \mathrm{L} 5-\mathrm{HT}$. Concentrationdependent vasorelaxation to the endothelium-independent vasodilator (SNP: $0.1 \mathrm{nmol} / \mathrm{L}-10 \mu \mathrm{mol} / \mathrm{L}$ ) was tested. Only experiments on vessels with SNP-induced relaxation being more than $95 \%$ were accounted as valid ${ }^{[28]}$.

\section{Determination of tissue $\left[\mathrm{Ca}^{2+}\right]_{i}$ in the mesenteric artery}

SD rats weighing 120-130 g were sacrificed by $\mathrm{CO}_{2}$, and the superior mesenteric arteries were gently removed. The arteries were immersed in cold HEPES-Krebs solution ( $\mathrm{pH} 7.4)$ of the following composition (mmol/L): $\mathrm{NaCl} 135, \mathrm{KCl} 5, \mathrm{MgSO}_{4}$ 1.2, $\mathrm{CaCl}_{2} 2.5$, glucose 10 and HEPES 8.4. Tissues adhering to the arteries were cleaned under a microscope. Each mesenteric artery was cut into ring segments with a length of about $3 \mathrm{~mm}$ and mounted on a U-shaped stainless steel wire. The artery rings with the wire were placed in the bottom of the chamber close to cover glass, followed by immediate immersion in HEPES-Krebs solution containing $10 \mu \mathrm{mol} / \mathrm{L}$ Fluo-3/AM, which was then added with DMSO, formononetin $(10 \mu \mathrm{mol} / \mathrm{L})$, formononetin $(100 \mu \mathrm{mol} / \mathrm{L})$ and verapamil $(1 \mu \mathrm{mol} / \mathrm{L})$, respectively. After $30 \mathrm{~min}$, the artery rings were washed three times with HEPES-Krebs solution ( $\mathrm{pH} 7.4)$ containing DMSO, formononetin (10 and $100 \mu \mathrm{mol} / \mathrm{L})$ and verapamil ( $1 \mu \mathrm{mol} / \mathrm{L})$, respectively. A real-time confocal microscope (FV1000, Olympus, Tokyo, Japan) was employed to obtain the fluorescent images. The image frame was continuously acquired every $1.107 \mathrm{~s}$, and the images were stored in a high-speed hard disk. The artery rings were observed immediately after dye loading to acquire the fluorescent images of the resting state. Following the acquisition of resting response, the specimens were exposed to $50 \mathrm{mmol} / \mathrm{L} \mathrm{KCl}$ and the images were acquired continuously ${ }^{[29]}$. The fluorescence intensity was calculated from individual image utilizing FV10ASW (version 1.7, Olympus, Tokyo, Japan), and the changes of fluorescence intensity versus time were plotted. The change rate $(\%)$ of fluorescence intensity induced by $\mathrm{KCl}$ was calculated based on the formula below:

[(fluorescence intensity after exposure to $\mathrm{KCl}$ - fluorescence intensity before exposure to $\mathrm{KCl}$ )/fluorescence intensity before exposure to $\mathrm{KCl}] \times 100$.

The change rate of fluorescence intensity reflected the change of $\left[\mathrm{Ca}^{2+}\right]_{i}$.

\section{Measurement of arterial pressure}

SHRs weighing 250-300 g were divided into 5 groups $(n=6-8$ per group). Arterial pressure measurement was carried out via a non-invasive tail-cuff plethysmography method (CODA 6 , Kent Scientific, Torrington, CT, USA) ${ }^{[30]}$ once every day for a succession of five days to get the rats adapted to the operation. Right before the drug administration, the arterial pressure was measured. Then formononetin (5, 10, and $20 \mathrm{mg} / \mathrm{kg}$ ), lacidipine $(0.06 \mathrm{mg} / \mathrm{kg})$ and saline containing $10 \%$ Tween 80 were injected via tail vein, respectively. The arterial pressure was assessed $0.5,1,2,3$, and $4 \mathrm{~h}$ after the administration.

\section{Statistical analysis}

Data are expressed as mean \pm SEM, and the differences between means were evaluated using SPSS for Windows 13.0 (SPSS, Chicago, IL, USA) ${ }^{[31]}$. Relaxant responses in each segment are expressed as a percentage of relaxation from the precontraction. $E_{\max }$ and $R_{\max }$ represent the maximal contraction and the maximal relaxation induced by vasoconstrictors and formononetin, respectively. Comparisons were made using 2-way ANOVA followed by Fischer's least significant difference post-hoc tests. Statistical significance was set at $P<0.05$. The $\mathrm{EC}_{50}$ was calculated by nonlinear regression analysis using the computer program GraphPad Prism 5 (San Diego, CA, USA).

\section{Results}

\section{Relaxing responses of arteries to formononetin}

$\mathrm{KCl}(60 \mathrm{mmol} / \mathrm{L})$ or U46619 $(1 \mathrm{\mu mol} / \mathrm{L})$ was added to the baths to induce precontraction of the segments of rat mesenteric arteries, renal arteries, cerebral arteries, coronary arteries and abdominal aortas, respectively. The segments of rat mesenteric arteries, renal arteries and abdominal aortas were precontracted by phenylephrine $(10 \mu \mathrm{mol} / \mathrm{L})$. After sustained contraction was obtained, formononetin (1-300 $\mu \mathrm{mol} / \mathrm{L})$ was added cumulatively to the baths. Formononetin elicited a concentration-dependent relaxation in the rat artery segments pre-contracted by $\mathrm{KCl}$ (Figure 1A, Table 1), U46619 (Figure 1B, Table 2) or phenylephrine (Figure 1C, Table 3).

Table 1. Relaxation responses induced by formononetin in rat arterial segments pre-contracted by $60 \mathrm{mmol} / \mathrm{L} \mathrm{K}^{+}$; supplemental data for Figure 1A. Data are expressed as mean \pm SEM. $n=6-8$. ${ }^{b} P<0.05,{ }^{c} P<0.01$ vs cerebral artery. ${ }^{f} P<0.01$ vs coronary artery.

\begin{tabular}{lcccc}
\hline \multicolumn{1}{c}{ Artery } & \multicolumn{3}{c}{ Formononetin } & $\begin{array}{c}\text { Control } \\
\text { (DMSO) }\end{array}$ \\
& $(\mathrm{mN})$ & $R_{\max }(\%)$ & $\mathrm{EC}_{50}(\mu \mathrm{mol} / \mathrm{L})$ & $R_{\max }(\%)$ \\
\hline Mesenteric artery & $7.19 \pm 0.42$ & $96.2 \pm 1.0^{\mathrm{b}}$ & $14.9 \pm 1.8^{\mathrm{cf}}$ & $7.3 \pm 2.2$ \\
Abdominal aorta & $9.01 \pm 0.71$ & $96.7 \pm 1.7^{\mathrm{b}}$ & $19.1 \pm 4.1^{\mathrm{cf}}$ & $7.2 \pm 4.1$ \\
Renal artery & $7.70 \pm 0.65$ & $93.4 \pm 2.0$ & $24.0 \pm 5.8$ & $5.6 \pm 2.8$ \\
Coronary artery & $5.31 \pm 0.56$ & $91.8 \pm 5.8$ & $36.3 \pm 3.5$ & $4.8 \pm 2.1$ \\
Cerebral artery & $5.30 \pm 0.52$ & $86.1 \pm 3.9$ & $37.9 \pm 4.9$ & $7.2 \pm 6.1$ \\
\hline
\end{tabular}

$R_{\max }$, maximum relaxation to formononetin or DMSO (control). 

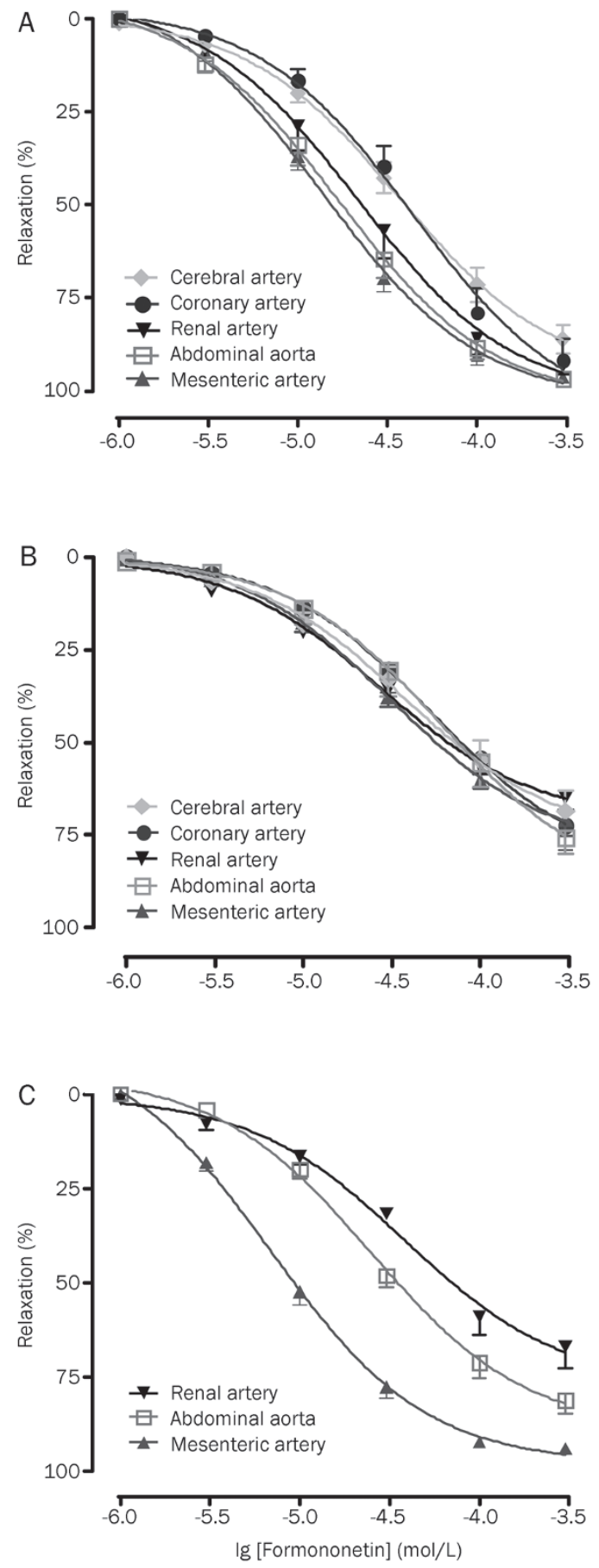

Figure 1. Cumulative concentration-response curves of formononetin. Rat isolated cerebral arteries, coronary arteries, renal arteries, abdominal aorta, and mesenteric arteries pre-contracted by $60 \mathrm{mmol} / \mathrm{L} \mathrm{K}^{+}(\mathrm{A})$ and $1 \mu \mathrm{mol} / \mathrm{L}$ U46619 (B), respectively; renal arteries, abdominal aorta, and mesenteric arteries pre-contracted by $10 \mu \mathrm{mol} / \mathrm{L}$ phenylephrine (C). Data are shown as mean \pm SEM. $n=7-8$ arteries.

\section{Involvement of endothelium}

Formononetin (1-300 $\mu \mathrm{mol} / \mathrm{L})$ concentration-dependently relaxed rat mesenteric artery segments pre-contracted by phenylephrine $(10 \mu \mathrm{mol} / \mathrm{L})$ with or without endothelium
Table 2. Relaxation responses induced by formononetin in rat arterial segments pre-contracted by $1 \mu \mathrm{mol} / \mathrm{L}$ U46619; supplemental data for Figure 1B. Data are expressed as mean \pm SEM. $n=6-8$.

\begin{tabular}{|c|c|c|c|c|}
\hline \multirow{2}{*}{ Artery } & \multirow{2}{*}{$\begin{array}{c}1 \mu \mathrm{mol} / \mathrm{L} \\
\mathrm{U} 46619 \\
(\mathrm{mN})\end{array}$} & \multicolumn{2}{|c|}{ Formononetin } & \multirow{2}{*}{$\begin{array}{c}\text { Control } \\
\text { (DMSO) } \\
R_{\max }(\%\end{array}$} \\
\hline & & $R_{\max }(\%)$ & $\mathrm{EC}_{50}(\mu \mathrm{mol} / \mathrm{L})$ & \\
\hline Mesenteric artery & $12.47 \pm 0.74$ & $73.8 \pm 3.1$ & $41.8 \pm 6.9$ & $2.9 \pm 3.5$ \\
\hline Abdominal aorta & $13.88 \pm 0.70$ & $75.8 \pm 4.3$ & $59.8 \pm 17.0$ & $6.0 \pm 2.2$ \\
\hline Renal artery & $10.65 \pm 0.63$ & $65.0 \pm 3.3$ & $33.8 \pm 6.5$ & $2.9 \pm 2.0$ \\
\hline Coronary artery & $5.55 \pm 0.66$ & $72.4 \pm 6.7$ & $68.6 \pm 21.3$ & $4.5 \pm 1.1$ \\
\hline Cerebral artery & $5.83 \pm 0.49$ & $68.6 \pm 5.7$ & $40.9 \pm 5.9$ & $5.7 \pm 1.2$ \\
\hline
\end{tabular}

$R_{\max }$, maximum relaxation to formononetin or DMSO (control).

Table 3. Relaxation responses induced by formononetin in rat arterial segments pre-contracted by $10 \mu \mathrm{mol} / \mathrm{L}$ phenylephrine (PE); supplemental data for Figure 1C. Data are expressed as mean \pm SEM. $n=6-8$. ${ }^{b} P<0.05$, ${ }^{\mathrm{c}} P<0.01$ vs renal artery. ${ }^{\mathrm{e}} P<0.05,{ }^{\mathrm{f}} P<0.01$ vs abdominal aorta.

\begin{tabular}{lcccc}
\hline \multicolumn{1}{c}{ Artery } & $\begin{array}{c}10 \mu \mathrm{mol} / \mathrm{L} \mathrm{PE} \\
(\mathrm{mN})\end{array}$ & \multicolumn{2}{c}{$\begin{array}{c}\text { Formononetin } \\
R_{\max }(\%)\end{array}$} & $\begin{array}{c}\text { Control } \\
(\mathrm{EMSO})\end{array}$ \\
\hline Mesenteric artery & $7.96 \pm 0.70$ & $94.0 \pm 1.5^{\mathrm{ce}}$ & $7.7 \pm 0.9^{\text {cf }}$ & $8.1 \pm 2.1$ \\
Abdominal aorta & $7.18 \pm 0.67$ & $81.3 \pm 3.5^{\mathrm{b}}$ & $24.3 \pm 1.9^{\mathrm{c}}$ & $6.7 \pm 1.5$ \\
$R_{\max }(\%)$
\end{tabular}

$R_{\max }$, maximum relaxation to formononetin or DMSO (control).

(Figure 2). Removal of endothelium suppressed the relaxing response to formononetin $\left(R_{\max }=96.25 \% \pm 1.72 \%\right.$ in endothelium-intact arteries, $R_{\max }=56.84 \% \pm 1.89 \%$ in endotheliumdenuded arteries, $P<0.05)$, suggesting that the vasodilatation was partially endothelium-dependent.

Effects of NOS and cyclo-oxygenase (COX) inhibitors on the relaxing response to formononetin

Before treatment with formononetin in phenylephrine (10 $\mu \mathrm{mol} / \mathrm{L}$ )-induced precontraction, rat mesenteric artery segments with endothelium were co-incubated with L-NAME (NOS inhibitor, $100 \mu \mathrm{mol} / \mathrm{L}$ ), indomethacin (COX inhibitor, $10 \mu \mathrm{mol} / \mathrm{L})$ or L-NAME $(100 \mu \mathrm{mol} / \mathrm{L})+$ indomethacin $(10 \mu \mathrm{mol} / \mathrm{L})$ for $20 \mathrm{~min}$. Figure 2 showed that $L$-NAME and L-NAME+indomethacin attenuated the concentrationresponse curves of formononetin, while indomethacin lightly attenuated the concentration-relaxation curves of formononetin.

\section{Effects of $\beta$-adrenoceptor and $\mathrm{K}^{+}$channels blockers on the relaxing response to formononetin}

Before the addition of formononetin and $60 \mathrm{mmol} / \mathrm{L} \mathrm{KCl}$ to the baths, the endothelium-denuded mesenteric artery segments were treated with propranolol $(1 \mu \mathrm{mol} / \mathrm{L})$, glibenclamide $(10 \mu \mathrm{mol} / \mathrm{L})$, tetraethylammonium $(300 \mu \mathrm{mol} / \mathrm{L})$ or bar- 


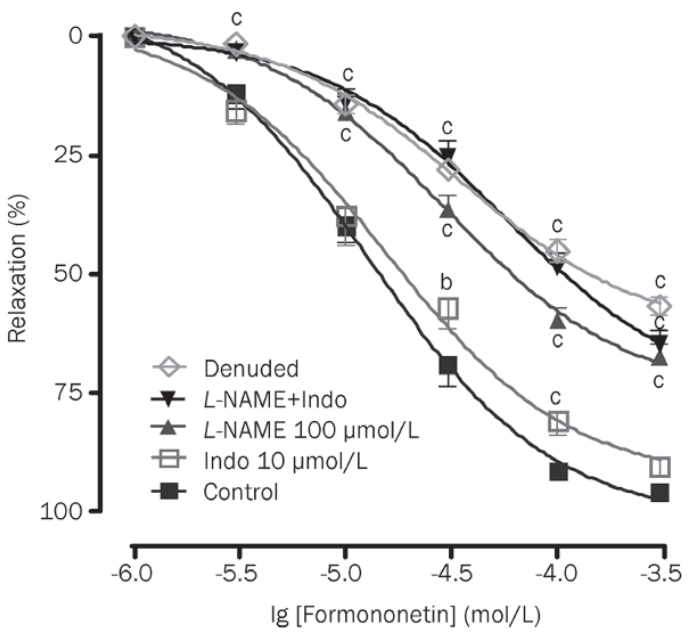

Figure 2. Effects of $L-N A M E(100 \mu \mathrm{mol} / \mathrm{L})$, indomethacin (Indo, $10 \mu \mathrm{mol} / \mathrm{L}$ ) and $L-N A M E+I n d o(100 \mu \mathrm{mol} / L+10 \mu \mathrm{mol} / \mathrm{L})$ on the relaxing responses induced by formononetin in mesenteric arteries with intact endothelium, and effects of formononetin on mesenteric arteries with endothelium denuded and with endothelium intact (control). Rat isolated mesenteric arteries were pre-contracted by phenylephrine. Data are shown as mean \pm SEM. $n=7-8$ arteries. ${ }^{b} P<0.05,{ }^{c} P<0.01$ vs control.

ium chloride $(10 \mu \mathrm{mol} / \mathrm{L})$ for $20 \mathrm{~min}$ in order to test whether or not $\beta$-adrenoceptors, ATP sensitive $\mathrm{K}^{+}$channels, calciumactivated $\mathrm{K}^{+}$channels and inwardly rectifying $\mathrm{K}^{+}$channels were involved in the formononetin-induced relaxation. As shown in Figure 3, these blockers, compared with control (in the absence of blockers), did not shift the concentrationrelaxation curves of formononetin significantly. No matter the blockers were present or not, the $R_{\max }$ and $\mathrm{EC}_{50}$ of formononetin in the endothelium-denuded artery segments showed no significant difference $(P>0.05)$.

\section{Effects of formononetin on $\mathrm{K}^{+}$-induced contraction}

Krebs solution was replaced with high $\mathrm{KCl}(10,20$, 40, and $80 \mathrm{mmol} / \mathrm{L}$ )-Krebs solutions $20 \mathrm{~min}$ after the treatment with DMSO (control) or formononetin (10, 30, and $100 \mu \mathrm{mol} / \mathrm{L})$. The concentration-contraction curves of the endotheliumdenuded rat mesenteric artery segments for $\mathrm{KCl}$ were constructed. Compared with control, formononetin shifted the concentration-contraction curves of $\mathrm{KCl}$ towards the right in a

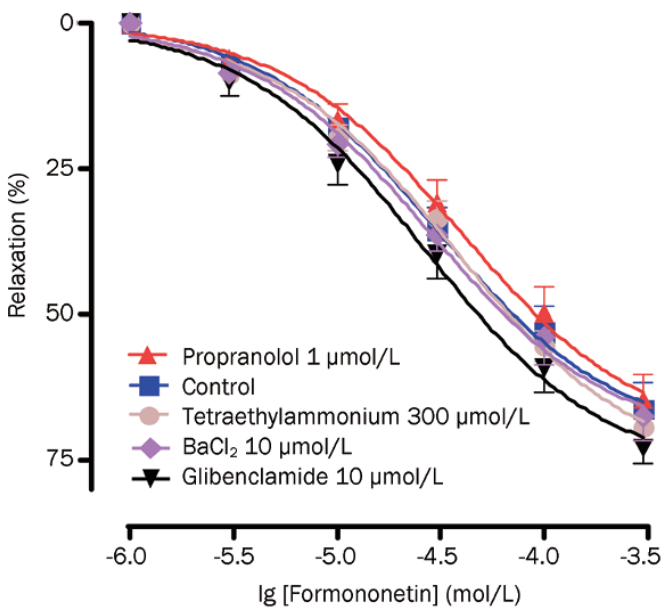

Figure 3. The vasorelaxant effect of formononetin in endothelium-free artery in the presence of propranolol $(1 \mu \mathrm{mol} / \mathrm{L})$, tetraethylammonium (300 $\mu \mathrm{mol} / \mathrm{L}), \mathrm{BaCl}_{2}(10 \mu \mathrm{mol} / \mathrm{L})$, or glibenclamide $(10 \mu \mathrm{mol} / \mathrm{L})$. Relaxation is expressed as a percentage of decrease in the maximal tension induced by $60 \mathrm{mmol} / \mathrm{L} \mathrm{K}^{+}$. Data are shown as mean \pm SEM. $n=7-8$ arteries. (control: in the absence of blockers)

non-parallel manner $(P<0.05$, Figure $4 \mathrm{~A})$. The $E_{\max }$ of vasoconstrictive response to $\mathrm{KCl}$ was decreased and the $\mathrm{EC}_{50}$ value of $\mathrm{KCl}$ was increased by formononetin $(P<0.05$, Table 4$)$.

\section{Effects of formononetin on $\mathrm{Ca}^{2+}$-induced contractions in $\mathrm{Ca}^{2+}$-free depolarized Krebs solution}

The endothelium-denuded rat mesenteric artery segments were exposed to $\mathrm{Ca}^{2+}$-free and $\mathrm{K}^{+}$-rich solution containing EDTA $(100 \mu \mathrm{mol} / \mathrm{L})$ and $\mathrm{KCl}(60 \mathrm{mmol} / \mathrm{L})$ for $20 \mathrm{~min}$. Then, $\mathrm{CaCl}_{2}(0.01-10 \mathrm{mmol} / \mathrm{L})$ was added cumulatively to the baths after treatment with DMSO (control) or formononetin (10, 30, and $100 \mu \mathrm{mol} / \mathrm{L}$ ) for $15 \mathrm{~min}$, and the concentration-response curves of $\mathrm{CaCl}_{2}$ were constructed. Formononetin, compared with control, shifted the concentration-response curves of $\mathrm{CaCl}_{2}$ towards the right in a non-parallel manner $(P<0.05$, Figure $4 \mathrm{~B}$ ). The $E_{\max }$ of vasoconstrictive response to $\mathrm{CaCl}_{2}$ was decreased and the $\mathrm{EC}_{50}$ value of $\mathrm{CaCl}_{2}$ was increased by formononetin $(P<0.05$, Table 4$)$.

\section{Effects of formononetin on phenylephrine- and 5-HT-induced} contraction

The endothelium-denuded rat mesenteric artery segments

Table 4. $\mathrm{EC}_{50}$ values of different agonists contracting rat mesenteric arteries without endothelium after incubation with formononetin (For). Data are expressed as mean \pm SEM. $n=6-8 .{ }^{b} P<0.05,{ }^{\mathrm{c}} P<0.01$ vs control (DMSO).

\begin{tabular}{|c|c|c|c|c|c|}
\hline \multirow[t]{2}{*}{ Agonist } & & \multicolumn{4}{|c|}{$\mathrm{EC}_{50}$ value } \\
\hline & & Control & For $10 \mu \mathrm{mol} / \mathrm{L}$ & For $30 \mu \mathrm{mol} / \mathrm{L}$ & For $100 \mu \mathrm{mol} / \mathrm{L}$ \\
\hline $\mathrm{KCl}$ & $\mathrm{mmol} / \mathrm{L}$ & $30.1 \pm 0.95$ & $31.7 \pm 0.6$ & $32.7 \pm 0.8^{b}$ & $38.0 \pm 0.8^{c}$ \\
\hline Phenylephrine & $\mu \mathrm{mol} / \mathrm{L}$ & $0.77 \pm 0.21$ & $0.95 \pm 0.25$ & $1.30 \pm 0.25$ & $1.42 \pm 0.19^{b}$ \\
\hline $5-\mathrm{HT}$ & $\mu \mathrm{mol} / \mathrm{L}$ & $0.77 \pm 0.14$ & $1.14 \pm 0.23$ & $1.23 \pm 0.18$ & $2.13 \pm 0.09^{c}$ \\
\hline
\end{tabular}



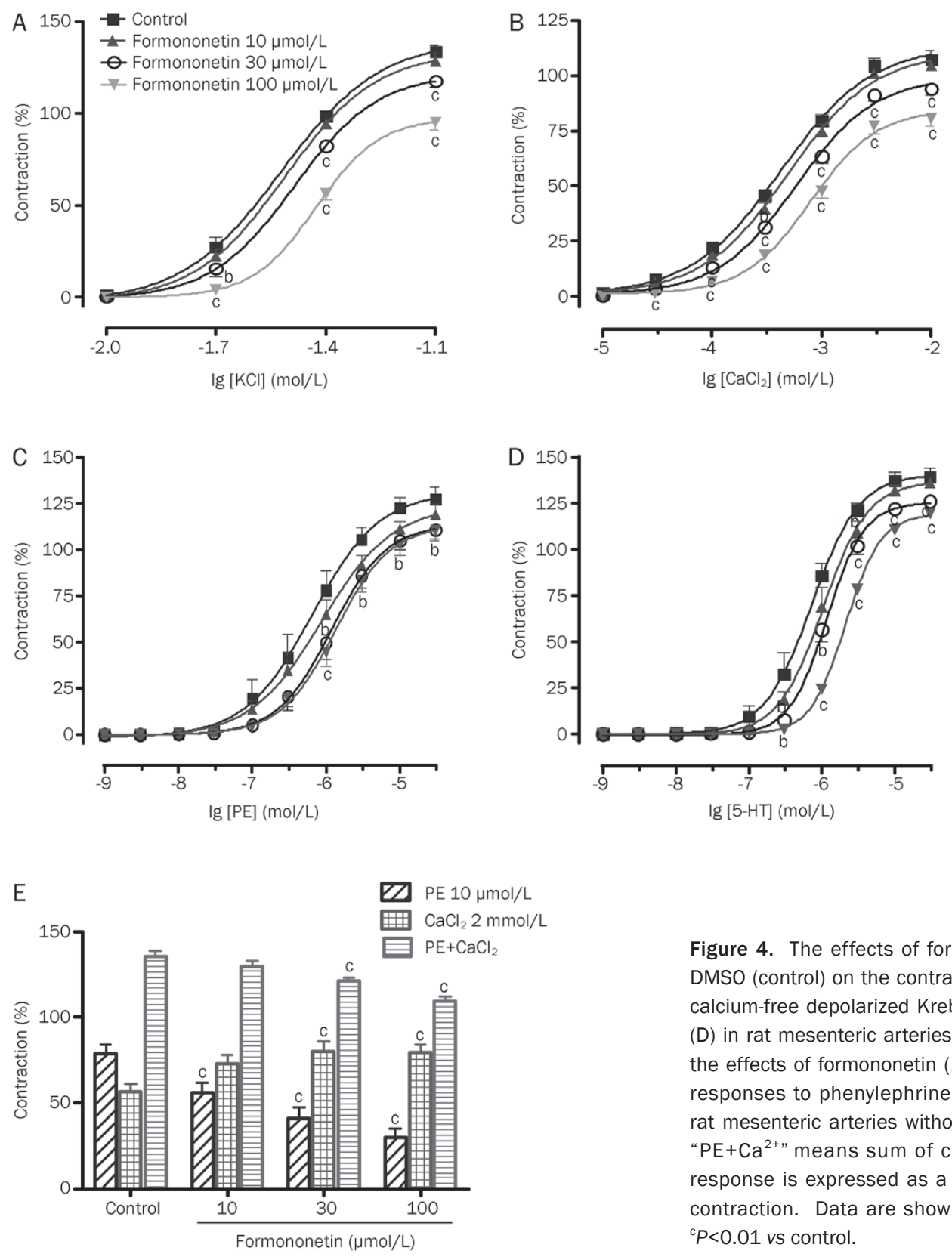

Figure 4. The effects of formononetin (10, 30, and $100 \mu \mathrm{mol} / \mathrm{L})$ and DMSO (control) on the contractile responses to potassium (A), calcium in calcium-free depolarized Krebs solution (B), phenylephrine (C), and 5-HT (D) in rat mesenteric arteries without endothelium. Bar graph (E) shows the effects of formononetin $(10,30$, and $100 \mu \mathrm{mol} / \mathrm{L})$ on the contractile responses to phenylephrine $(\mathrm{PE}, 10 \mu \mathrm{mol} / \mathrm{L})$ and $\mathrm{CaCl}_{2}(2 \mathrm{mmol} / \mathrm{L})$ in rat mesenteric arteries without endothelium in $\mathrm{Ca}^{2+}$-free Krebs solution. "PE $+\mathrm{Ca}^{2+"}$ means sum of contractions to $\mathrm{PE}$ and $\mathrm{Ca}^{2+}$. Contractile response is expressed as a percentage of the $60 \mathrm{mmol} / \mathrm{L} \mathrm{K}^{+}$induced contraction. Data are shown as mean \pm SEM. $n=8$ arteries. ${ }^{b} P<0.05$, ${ }^{\mathrm{c}} \mathrm{P}<0.01$ vs control.

were pre-treated with DMSO (control) or formononetin $(10,30$, and $100 \mathrm{\mu mol} / \mathrm{L})$ for $20 \mathrm{~min}$. Phenylephrine or 5-HT (0.001-30 $\mu \mathrm{mol} / \mathrm{L})$ was cumulatively added to the baths. Formononetin inhibited the phenylephrine- or 5-HT-induced vasoconstriction and concentration-dependently shifted the concentrationcontraction curves towards the right in a non-parallel manner with a decreased $E_{\max }$ (Figure $4 \mathrm{C}, 4 \mathrm{D}$ ). The $\mathrm{EC}_{50}$ of phenylephrine and 5-HT were increased by formononetin $(P<0.05$, Table 4).

Effects of formononetin on the contraction induced by phenylephrine dependent upon intracellular and extracellular calcium

The endothelium-denuded rat mesenteric artery segments were exposed to $\mathrm{Ca}^{2+}$-free Krebs solution containing DMSO (control) or formononetin $(10,30$, and $100 \mu \mathrm{mol} / \mathrm{L})$ for $10 \mathrm{~min}$ in order to remove the extracellular $\mathrm{Ca}^{2+}$, followed by addition of $10 \mu \mathrm{mol} / \mathrm{L}$ phenylephrine inducing phasic contractions caused by the release of intracellular $\mathrm{Ca}^{2+}$. When the maximal contraction was obtained, $\mathrm{CaCl}_{2}$ of $2 \mathrm{mmol} / \mathrm{L}$ was added to induce a tonic contraction evoked by the extracellular $\mathrm{Ca}^{2+}$ influx ${ }^{[32]}$. The results showed formononetin concentrationdependently inhibited the contraction induced by phenylephrine, but increased the $\mathrm{CaCl}_{2}$-induced contraction (Figure $4 \mathrm{E}$ ).

Effects of formononetin on the contraction induced by caffeine in $\mathrm{Ca}^{2+}$-free solution

After the endothelium-denuded rat mesenteric artery segments were incubated with DMSO or formononetin (100 
$\mu \mathrm{mol} / \mathrm{L})$ for $20 \mathrm{~min}$ in $\mathrm{Ca}^{2+}$-free medium, artery contractions to caffeine $(30 \mathrm{mmol} / \mathrm{L})$ were obtained. The contractions induced by caffeine in the presence or absence of formononetin were $18.3 \% \pm 1.8 \%$ and $18.0 \% \pm 1.7 \%$ (contractile response is expressed as a percentage of the contraction induced by 60 $\mathrm{mmol} / \mathrm{L} \mathrm{K}^{+}$), respectively. These data showed that formononetin did not affect the vasoconstriction induced by caffeine in $\mathrm{Ca}^{2+}$-free solution ( $n=8$ arteries, $P>0.05$ ).

\section{Effects of formononetin on $\mathrm{Ca}^{2+}$ fluorescence intensity in rat mesenteric artery}

Figure 5 presented the time course of the change rate of fluorescence intensity induced by $50 \mathrm{mmol} / \mathrm{L} \mathrm{KCl}$ in rat mesenteric arteries. It could be seen that formononetin (10 and 100 $\mu \mathrm{mol} / \mathrm{L}$ ) concentration-dependently inhibited the change rate of fluorescence intensity.

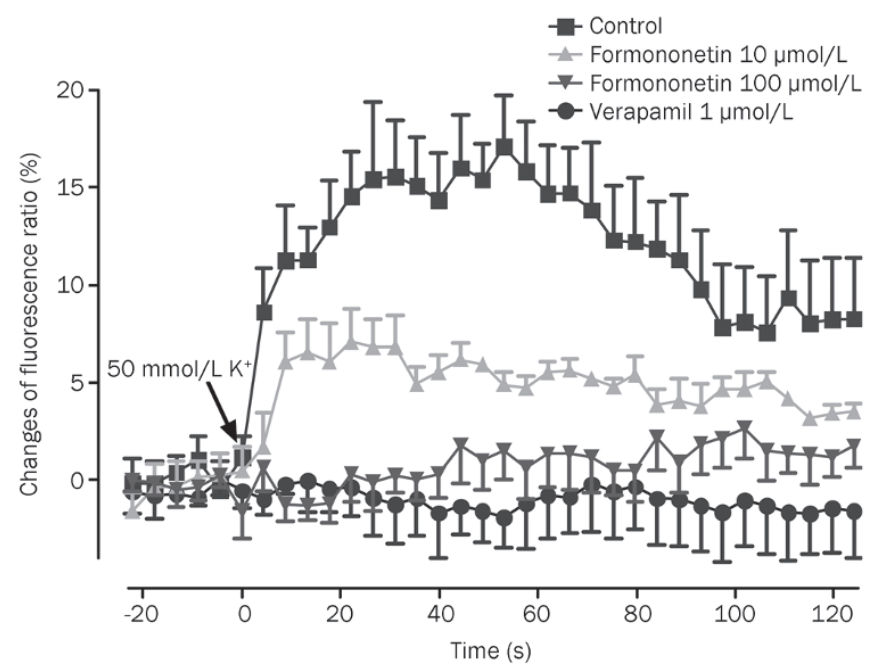

Figure 5. Effects of formononetin (10 and $100 \mu \mathrm{mol} / \mathrm{L}$ ), verapamil $\left(1 \mu \mathrm{mol} / \mathrm{L}\right.$ ), and DMSO (control) on $\mathrm{Ca}^{2+}$ fluorescence intensity in rat mesenteric arteries. The change rate of fluorescence intensity reflexes the change of intracellular $\mathrm{Ca}^{2+}$ concentration $\left(\left[\mathrm{Ca}^{2+}\right]_{\mathrm{i}}\right)$. Each point represents the mean $\pm S E M$ of five experiments.

\section{Effects of formononetin on the SHR arterial pressure}

The SHR arterial pressure was determined before drug administration. Then formononetin $(5,10$, and $20 \mathrm{mg} / \mathrm{kg})$, lacidipine $(0.06 \mathrm{mg} / \mathrm{kg}$ ) and saline containing $10 \%$ Tween 80 (control) were injected via tail vein. The arterial pressure was measured $0.5,1,2,3$, and $4 \mathrm{~h}$ after injection. It was found that formononetin lowered the systolic, diastolic and mean arterial pressures of the SHRs (Figure 6). The decline of arterial pressure reached the peak at 2 to $3 \mathrm{~h}$ after the treatment with formononetin, while the peak of the pressure decline induced by lacidipine was at $30 \mathrm{~min}$ after treatment.

\section{Discussion}

There have already been many reports about the antihyper-
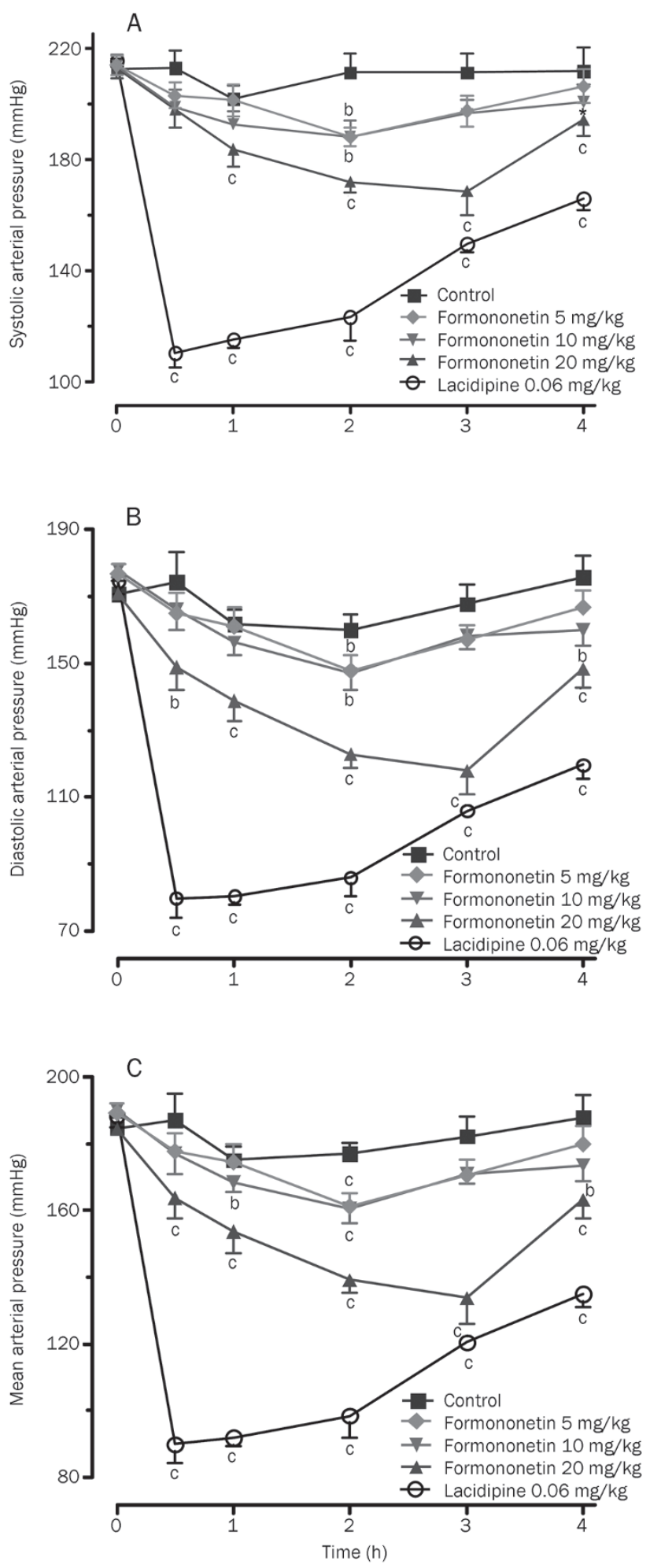

Figure 6. The effects of formononetin $(5,10$, and $20 \mathrm{mg} / \mathrm{kg})$, lacidipine (0.06 mg/kg), and saline containing 10\% Tween 80 (control) on systolic arterial pressure (A), diastolic arterial pressure (B) and mean arterial pressure $(C)$ of the SHRs. Formononetin and lacidipine were intravenously administered. Data are shown as mean \pm SEM. $n=8 .{ }^{b} P<0.05,{ }^{c} P<0.01$ vs control. 
tensive effects of some isoflavones ${ }^{[11]}$. However, no pharmacological or clinical study has been carried out to test the antihypertensive properties of formononetin. Our study first investigated the antihypertensive potential of formononetin, and the results show that formononetin can lower the arterial pressure in SHRs.

One of the key mechanisms of antihypertensive drugs is to lower the vascular resistance by directly dilating the blood vessels. Our experimental results show that formononetin can relax the arteries pre-contracted by vasoconstrictors, indicating that the antihypertensive activities of formononetin maybe stem from the vasorelaxant activity. This is in concert with the previous findings that formononetin relaxes rat isolated aorta ${ }^{[9]}$ and some isoflavones have vasorelaxant activities ${ }^{[15]}$. We have found that mesenteric artery is more sensitive to formononetin than abdominal aorta and renal artery in precontraction by phenylephrine, and meanwhile mesenteric artery is one of peripheral arteries which contribute more resistance than aorta in hypertension, and therefore we chose to study the vasorelaxant mechanism of formononetin on mesenteric artery.

The vasorelaxant activity of antihypertensive drugs is achieved by influencing both vascular endothelial and vascular smooth muscle cells. Endothelium plays an important role in regulating the function of cardiovascular system. It synthesizes and releases several vasodilator substances, mainly including vasodilator PGs, NO, and $\mathrm{EDHF}^{[33]}$. The removal of endothelium markedly attenuates the relaxant response of arteries to formononetin, suggesting that the relaxation is endothelium-dependent. NO causes vascular relaxation by stimulating the production of cGMP and/or causing membrane hyperpolarization ${ }^{[34]}$. L-NAME, a NOS inhibitor, inhibits the relaxation of formononetin, indicating that the vasorelaxant activity of formononetin is related to NO release. Similar findings are reported elsewhere ${ }^{[9]}$. The vasorelaxant effect of PGs is realized through increasing intracellular cAMP levels ${ }^{[35]}$. We have found that indomethacin has little effect on the concentration-relaxation curves of formononetin, and therefore PG biosynthesis is little involved in the formononetin-induced relaxation. EDHF dilates arteries by increasing the membrane permeability of vascular smooth muscle cells to $\mathrm{K}^{+[35]}$. The formononetin-induced relaxation in the mesenteric arteries without endothelium is not significantly different from that in the mesenteric arteries incubated with indomethacin $+L-N A M E$, suggesting that other factors like EDHF are not involved in the endothelium-dependent relaxation. The relaxing response to formononetin has remained after the denudation of endothelial cells, indicating the involvement of endothelium-independent mechanism. Thus, it is conceivable that formononetin directly act on vascular smooth muscles as well as endothelial cells.

Vascular smooth muscle cells are also contributory to the vasorelaxant activity of antihypertensive drugs. $\beta$-adrenoceptors and $\mathrm{K}^{+}$channels are important regulators of arterial tone. $\beta$-adrenoceptor-induced relaxation is mediated by the increase of the intracellular cAMP concentration and/ or activation of $\mathrm{K}^{+}$channels ${ }^{[36]}$. Opening of $\mathrm{K}^{+}$channels leads to membrane potential hyperpolarization and closure of voltage-dependent channels, which decreases $\mathrm{Ca}^{2+}$ entry and causes vasodilation $^{[37]}$. In our experiments, propranolol, glibenclamide, tetraethylammonium and $\mathrm{BaCl}_{2}$ did not affect the endothelium-independent relaxant response to formononetin in rat mesenteric arteries, suggesting that the $\mathrm{K}^{+}$channels and $\beta$-adrenoceptors are not involved in the vascular relaxation processes, which is in accordance with the previous findings that $\mathrm{K}^{+}$channel inhibitors did not affect the relaxation of genistein and zearalanone, two phytoestrogens, in rabbit coronary arteries ${ }^{[38]}$. By contrast, Wu et al proposed that formononetin caused opening of iberiotoxin-sensitive $\mathrm{Ca}^{2+}$-activated $\mathrm{K}^{+}$ channels and glibenclamide-sensitive adenosine triphosphate (ATP)-dependent $\mathrm{K}^{+}$channels in rat aorta ${ }^{[9]}$. This discordance may lie in the different responses of mesenteric artery and aorta to drugg ${ }^{[39]}$.

There are two kinds of $\mathrm{Ca}^{2+}$ channels in smooth muscle cells: VDCC and receptor-operated $\mathrm{Ca}^{2+}$ channels (ROCC). $\mathrm{KCl}$-induced contraction is due to membrane depolarization, leading to increased $\mathrm{Ca}^{2+}$ influx through VDCC. Formononetin inhibits the contraction induced by $\mathrm{KCl}$ in Krebs solution and $\mathrm{CaCl}_{2}$ in high- $\mathrm{K}^{+}$depolarization medium, suggesting that formononetin may inhibit VDCC. This is in accordance with some previous finding ${ }^{[38]}$.

Phenylephrine- or 5-HT-induced contraction in solution containing $\mathrm{Ca}^{2+}$ is due to activation of $\mathrm{a}_{1}$-adrenoceptors or 5-HT receptors, which leads to an increase in intracellular calcium concentration via activation of the inositol phosphate cascade, releasing intracellular calcium and promoting the entry of extracellular calcium through ROCC ${ }^{[40,41]}$. In the present study, formononetin treatment results in a rightward shift of concentration-contraction curves of phenylephrine or 5-HT in a non-parallel manner in medium with $\mathrm{Ca}^{2+}$, suggesting that formononetin can inhibit ROCC or $\mathrm{Ca}^{2+}$ release from intracellular stores. Our further experiments show that formononetin inhibits the contraction induced by phenylephrine in $\mathrm{Ca}^{2+}$-free solution while the tonic contraction evoked by the extracellular $\mathrm{Ca}^{2+}$ influx is increased, but the total contraction induced by $\mathrm{CaCl}_{2}$ and phenylephrine is decreased by formononetin. These results suggest that formononetin inhibits intracellular $\mathrm{Ca}^{2+}$ release from $\mathrm{Ca}^{2+}$ stores in vascular smooth muscle cells, but does not inhibit the extracellular $\mathrm{Ca}^{2+}$ influxing through ROCC. This is partly consistent with some previous findings ${ }^{[42]}$. The increased contraction induced by $\mathrm{CaCl}_{2}$ may be a compensatory mechanism of suppressed $\mathrm{Ca}^{2+}$ release. Thus, it is likely that $\mathrm{Ca}^{2+}$ mobilization in smooth muscle cells is inhibited by formononetin.

The release of intracellular $\mathrm{Ca}^{2+}$ is mainly regulated by ryanodine receptor system and inositol 1,4,5-trisphosphate (IP3) receptor system. The former may function through a $\mathrm{Ca}^{2+}$-induced $\mathrm{Ca}^{2+}$ release mechanism when the receptors are activated by caffeine ${ }^{[43]}$. The latter induces $\mathrm{Ca}^{2+}$ release directly when the receptors are bound to IP3. Furthermore, formononetin does not affect the caffeine-induced contraction in endothelium-denuded arteries, which rules out the possible involvement of ryanodine receptors. Therefore, it is likely that 
the IP3 receptor contributes to $\mathrm{Ca}^{2+}$ release.

Laser scanning confocal microscope and fluorescent probe are widely employed to monitor dynamic changes of $\left[\mathrm{Ca}^{2+}\right]_{\mathrm{i}}$ in various cells and tissues ${ }^{[29]}$. Our finding that formononetin inhibits the $\mathrm{KCl}$-induced increase of $\left[\mathrm{Ca}^{2+}\right]_{\mathrm{i}}$ in rat mesenteric artery further proves that formononetin decreases intracellular calcium.

In summary, formononetin, with antihypertensive potential, has multiple targets and a moderate effect in lowering arterial pressure, which is different from typical antihypertensive drugs. Besides, being a natural compound, formononetin may have little toxic effect. What's more, formononetin possesses antioxidant property ${ }^{[4]}$, and it increases the expression of eNOS ${ }^{[9]}$ and lowers blood lipid ${ }^{[45]}$, which will be beneficial in preventing and treating the complications of hypertension, such as cardiac and vascular remodeling, lipid abnormalities and atherosclerosis. Therefore, formononetin may be of value in treating and preventing hypertension.

\section{Acknowledgements}

This study was supported by grant from the National Natural Science Foundation of China (№ 30772566).

\section{Author contribution}

Tao SUN and Yong-xiao CAO designed the research; Tao SUN and Rui LIU performed the experiments; and Tao SUN and Yong-xiao CAO analyzed the data and wrote the paper.

\section{References}

1 Ogihara T, Matsuzaki M, Matsuoka H, Shimamoto K, Shimada K, Rakugi $\mathrm{H}$, et al. The combination therapy of hypertension to prevent cardiovascular events (COPE) trial: rationale and design. Hypertension Res 2005; 28: 331-8.

2 Yeh CT, Huang WH, Yen GC. Antihypertensive effects of Hsian-tsao and its active compound in spontaneously hypertensive rats. J Nutr Biochem 2009; 20: 866-75.

3 Kwan CY. Vascular effects of selected antihypertensive drugs derived from traditional medicinal herbs. Clin Exp Pharmacol Physiol Suppl 1995; 22: S297-9.

4 Ryu SY, Oh KS, Kim YS, Lee BH. Antihypertensive, vasorelaxant and inotropic effects of an ethanolic extract of the roots of Saururus chinensis. J Ethnopharmacol 2008; 118: 284-9.

5 Atkinson C, Compston JE, Day NE, Dowsett M, Bingham SA. The effects of phytoestrogen isoflavones on bone density in women: a double-blind, randomized, placebo-controlled trial. Am J Clin Nutr 2004; 79: 326-33.

6 Jarred RA, Keikha M, Dowling C, McPherson SJ, Clare AM, Husband $\mathrm{AJ}$, et al. Induction of apoptosis in low to moderate-grade human prostate carcinoma by red clover-derived dietary isoflavones. Cancer Epidemiol Biomarkers Prev 2002; 11: 1689-96.

7 Nestel P, Fujii A, Zhang L. An isoflavone metabolite reduces arterial stiffness and blood pressure in overweight men and postmenopausal women. Atherosclerosis 2007; 192: 184-9.

8 Ososki AL, Kennelly EJ. Phytoestrogens: a review of the present state of research. Phytother Res 2003; 17: 845-69.

$9 \mathrm{Wu} J \mathrm{H}, \mathrm{Li}$ Q, Wu MY, Guo DJ, Chen HL, Chen SL, et al. Formononetin, an isoflavone, relaxes rat isolated aorta through endothelium-dependent and endothelium-independent pathways. J Nutr Biochem 2009;
21: 613-20.

10 Chin-Dusting JP, Boak L, Husband A, Nestel PJ. The isoflavone metabolite dehydroequol produces vasodilatation in human resistance arteries via a nitric oxide-dependent mechanism. Atherosclerosis 2004; 176: 45-8.

11 Adlercreutz H, Hamalainen E, Gorbach S, Goldin B. Dietary phytooestrogens and the menopause in Japan. Lancet 1992; 339: 1233.

12 Breinholt V, Hossaini A, Svendsen GW, Brouwer C, Nielsen E. Estrogenic activity of flavonoids in mice. The importance of estrogen receptor distribution, metabolism and bioavailability. Food Chem Toxicol 2000; 38: 555-64.

13 Reinli K, Block G. Phytoestrogen content of foods - a compendium of literature values. Nutr Cancer 1996; 26: 123-48.

14 Tham DM, Gardner CD, Haskell WL. Clinical review 97: potential health benefits of dietary phytoestrogens: a review of the clinical, epidemiological, and mechanistic evidence. J Clin Endocrinol Metab 1998; 83: 2223-35.

15 Chin-Dusting JP, Fisher L, Lewis TV, Piekarska A, Nestel PJ, Husband A. The vascular activity of some isoflavone metabolites: implications for a cardioprotective role. Br J Pharmacol 2001; 133: 595-605.

16 Walker HA, Dean TS, Sanders TA, Jackson G, Ritter JM, Chowienczyk PJ. The phytoestrogen genistein produces acute nitric oxidedependent dilation of human forearm vasculature with similar potency to 17 beta-estradiol. Circulation 2001; 103: 258-62.

17 Ma W, Nomura M, Takahashi-Nishioka T, Kobayashi S. Combined effects of fangchinoline from Stephania tetrandra Radix and formononetin and calycosin from Astragalus membranaceus Radix on hyperglycemia and hypoinsulinemia in streptozotocin-diabetic mice. Biol Pharm Bull 2007; 30: 2079-83.

18 Ma X, Tu P, Chen Y, Zhang T, Wei Y. Preparative isolation and purification of calycosin and formononetin from Astragalus membranaceus Bge var mongholicus (Bge) Hsiao by high-speed counter-current chromatography. Se Pu 2005; 23: 299-301.

19 Reiners W. 7-hydroxy-4'-methoxy-isoflavone (formononetin) from liquorice root. On substances contained in liquorice root. II. Experientia 1966; 22: 359.

20 Avula B, Wang YH, Smillie TJ, Khan IA. Quantitative determination of triterpenoids and formononetin in rhizomes of black cohosh (Actaea racemosa) and dietary supplements by using UPLC-UV/ELS detection and identification by UPLC-MS. Planta Med 2009; 75: 381-6.

21 Jiang B, Kronenberg F, Balick MJ, Kennelly EJ. Analysis of formononetin from black cohosh (Actaea racemosa). Phytomedicine 2006; 13: $477-86$.

22 Schultz G. Isoflavone glucoside formononetin-7-glucoside and biochanin A-7-glucoside in Trifolium pratense L. Naturwissenschaften 1965; 52: 517

23 Zhang BQ, Hu SJ, Qiu LH, Zhu JH, Xie XJ, Sun J, et al. Effects of Astragalus membranaceus and its main components on the acute phase endothelial dysfunction induced by homocysteine. Vasc Pharmacol 2007; 46: 278-85.

24 Adner M, Cantera L, Ehlert F, Nilsson L, Edvinsson L. Plasticity of contractile endothelin-B receptors in human arteries after organ culture. Br J Pharmacol 1996; 119: 1159-66.

25 Sandhu H, Xu CB, Edvinsson L. Upregulation of contractile endothelin type $B$ receptors by lipid-soluble cigarette smoking particles in rat cerebral arteries via activation of MAPK. Toxicol Appl Pharmacol 2010; 249: 25-32.

26 Cao YX, Zheng JP, He JY, Li J, Xu CB, Edvinsson L. Induces vasodilatation of rat mesenteric artery in vitro mainly by inhibiting receptormediated $\mathrm{Ca}^{2+}$-influx and $\mathrm{Ca}^{2+}$-release. Arch Pharm Res 2005; 28 : 709-15. 
27 Cao YX, Zhang W, He JY, He LC, Xu CB. Ligustilide induces vasodilatation via inhibiting voltage dependent calcium channel and receptormediated $\mathrm{Ca}^{2+}$ influx and release. Vascul Pharmacol 2006; 45: 171-6.

28 Wiest R, Jurzik L, Moleda L, Froh M, Schnabl B, von Horsten S, et al. Enhanced $Y 1$-receptor-mediated vasoconstrictive action of neuropeptide $Y$ (NPY) in superior mesenteric arteries in portal hypertension. J Hepatol 2006; 44: 512-9.

29 Hashimoto T, Ohata H, Nobe K, Sakai Y, Honda K. A novel approach for the determination of contractile and calcium responses of the basilar artery employing real-time confocal laser microscopy. J Pharmacol Toxicol Methods 2007; 56: 79-86.

30 Nguyen P, Peltsch H, de Wit J, Crispo J, Ubriaco G, Eibl J, et al. Regulation of the phenylethanolamine $\mathrm{N}$-methyltransferase gene in the adrenal gland of the spontaneous hypertensive rat. Neurosci Lett 2009; 461: 280-4.

31 Inc S. SPSS Base 13.0 for Windows: Users Guide 2004.

32 Broekaert A, Godfraind T. A comparison of the inhibitory effect of cinnarizine and papaverine on the noradrenaline- and calcium-evoked contraction of isolated rabbit aorta and mesenteric arteries. Eur J Pharmacol 1979; 53: 281-8.

33 Kawabata A, Nakaya Y, Ishiki T, Kubo S, Kuroda R, Sekiguchi F, et al. Receptor-activating peptides for PAR-1 and PAR-2 relax rat gastric artery via multiple mechanisms. Life Sci 2004; 75: 2689-702.

34 Bonaventura D, Oliveira FS, Lunardi CN, Vercesi JA, da Silva RS, Bendhack LM. Characterization of the mechanisms of action and nitric oxide species involved in the relaxation induced by the ruthenium complex. Nitric Oxide 2006; 15: 387-94.

35 Higueras J, Sarria B, Ortiz JL, Cortijo J, Maruenda A, Barbera M, et al. Halothane inhibits endothelium-dependent relaxation elicited by acetylcholine in human isolated pulmonary arteries. Eur J Pharmacol 1997; 326: 175-81.
36 Huang Y, Kwok KH. Beta-adrenoceptor-mediated relaxation inhibited by tetrapentylammonium ions in rat mesenteric artery. Life Sci 1998; 62: PL19-25.

37 Mustafa S, Thulesius O. Hyperthermia-induced vasoconstriction of the carotid artery and the role of potassium channels. J Stroke Cerebrovasc Dis 2005; 14: 122-6.

38 Figtree GA, Griffiths H, Lu YQ, Webb CM, MacLeod K, Collins P. Plant-derived estrogens relax coronary arteries in vitro by a calcium antagonistic mechanism. J Am Coll Cardiol 2000; 35: 1977-85.

39 Chan HY, Yao X, Tsang SY, Chan FL, Lau CW, Huang Y. Different role of endothelium/nitric oxide in 17beta-estradiol- and progesteroneinduced relaxation in rat arteries. Life Sci 2001; 69: 1609-17.

40 Ford WR, Broadley KJ. Effects of adenosine receptor agonists on induction of contractions to phenylephrine of guinea-pig aorta mediated via intra- or extracellular calcium. Gen Pharmacol 1999; 33: $143-50$.

41 Hirafuji M, Ebihara T, Kawahara F, Hamaue N, Endo T, Minami M. Inhibition by docosahexaenoic acid of receptor-mediated $\mathrm{Ca}^{2+}$ influx in rat vascular smooth muscle cells stimulated with 5-hydroxytryptamine. Eur J Pharmacol 2001; 427: 195-201.

42 Ajay M, Gilani AU, Mustafa MR. Effects of flavonoids on vascular smooth muscle of the isolated rat thoracic aorta. Life Sci 2003; 74 : 603-12.

43 Leijten PA, van Breemen C. The effects of caffeine on the noradrenaline-sensitive calcium store in rabbit aorta. J Physiol 1984; 357: 327-39.

$44 \mathrm{Mu} \mathrm{H}$, Bai YH, Wang ST, Zhu ZM, Zhang YW. Research on antioxidant effects and estrogenic effect of formononetin from Trifolium pratense (red clover). Phytomedicine 2009; 16: 314-9.

45 Wang QY, Meng QH, Zhang ZT, Tian ZJ, Liu H. Synthesis, solubility, lipids-lowering and liver-protection activities of sulfonated formononetin. Yao Xue Xue Bao 2009; 44: 386-9. 